\title{
Adolescent life in low income and slum areas of Addis Ababa, Ethiopia
}

Annabel Erulkar

Population Council

Tekle-Ab Mekbib

Population Council

Negussie Simie

Tsehai Gulema

Follow this and additional works at: https://knowledgecommons.popcouncil.org/departments_sbsr-pgy

Part of the Family, Life Course, and Society Commons, Inequality and Stratification Commons, International Public Health Commons, and the Maternal and Child Health Commons How does access to this work benefit you? Let us know!

\section{Recommended Citation}

Erulkar, Annabel, Tekle-Ab Mekbib, Negussie Simie, and Tsehai Gulema. 2004. "Adolescent life in low income and slum areas of Addis Ababa, Ethiopia." Accra: Population Council. 


\section{Adolescent Life}

in Low Income \& Slum Areas

of Addis Ababa Ethiopia
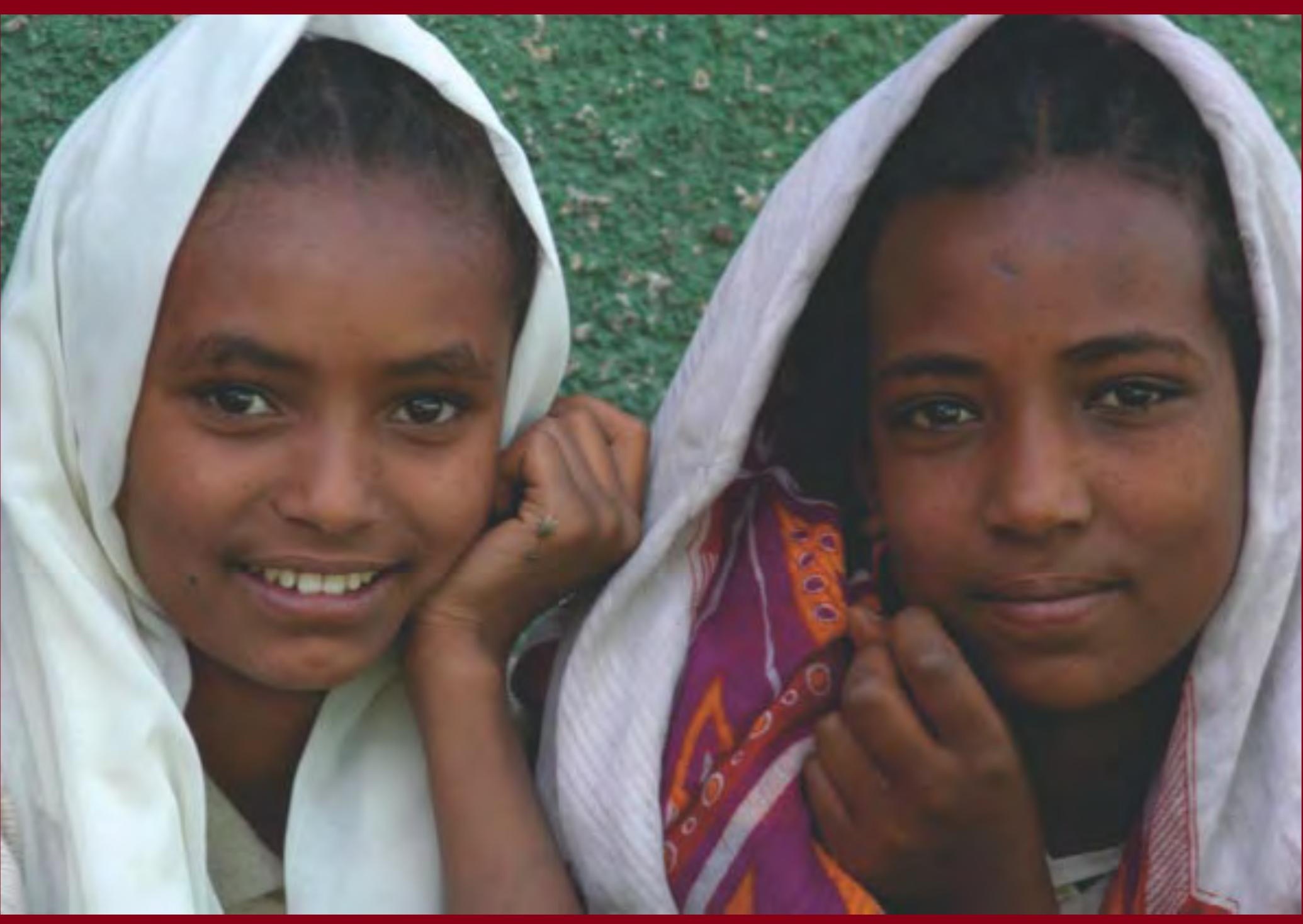


\title{
Adolescent Life in Low Income \& Slum Areas of Addis Ababa EThiopia
}

\author{
Annabel S. Erulkar \\ Tekle-Ab Mekbib \\ Negussie Simie \\ Tsehai Gulema
}




\section{(2) Population Council}

The Population Council is an international, nonprofit, nongovernmental organization that seeks to improve the wellbeing and reproductive health of current and future generations around the world and to help achieve a humane, equitable, and sustainable balance between people and resources. The Council conducts biomedical, social science, and public health research and helps build research capacities in developing countries. Established in 1952, the Council is governed by an international board of trustees. Its New York headquarters supports a global network of regional and country offices.

(c) 2004 by The Population Council

Population Council

P.O. BOX CT 4906

Accra, GHANA

Tel: (233) $21-780712 / 2$

Fax: (233) $21-780713$

\author{
Population Council \\ One Dag Hammarskjold Plaza \\ New York, NY 10017 USA \\ Tel: 212-339-0500 \\ Fax: 212-755-6052 \\ http://www.popcouncil.org
}

Annabel S. Erulkar, PhD is Program Associate at the Population Council's Regional Office for sub-Saharan Africa in Accra, Ghana.

Tekle-Ab Mekbib, MD, PhD, is Medical Consultant for the Population Council in Addis Ababa, Ethiopia.

Negussie Simie, MA, is Head of the Planning, Programming and Training Department, Ministry of Youth Sports and Culture, Ethiopia

Tsehai Gulema, MA is Head of the Youth Policy, Research and Implementation Department, Ministry of Youth Sports and Culture, Ethiopia

Photo credits: All photos courtesy of UNICEF Ethiopia 


\section{FORWARD}

The rights and well-being of the children and youth are firmly held values of the Federal Democratic Republic of Ethiopia (FDRE). The recently proclaimed Youth Policy by the Government of the FDRE is a manifestation of this commitment, and is indeed a historical milestone in the effort to improve the lives of adolescents and young people in the country. Ethiopia is a signatory to the Convention on the Rights of the Child and fully supports the International Conference on Population and Development (ICPD) recommendations making adolescent reproductive health an area of special attention.

As such, the Ministry of Youth, Sports and Culture has long considered attention to the lives of Ethiopian adolescents as a priority intervention area for research and programs in the country. This study gives critical insight into the lives of adolescent girls and boys in Ethiopia. Whereas youth programs tend to treat all adolescents as similar, or indeed homogeneous, the findings of this study highlight the remarkable diversity of young people in Ethiopia. The study highlights that many young people live without parents; that many are out of school while they value education; that many adolescents are survival workers who are at risk of exploitation and abuse; and that marriage can be an unwanted event in the lives of adolescent girls. The study teaches us to recognize that not all adolescents are the same and that some adolescents are in highly vulnerable situations, such as domestic workers and victims of forced early marriage. Likewise, the study teaches us that programming for young people needs to recognize this diversity, and move toward finetuning models to reach the most vulnerable, at-risk youth.

It is the hope of the Ministry of Youth, Sports and Culture that the findings from this study can be fully integrated into appropriate programs for Ethiopian girls and boys in all areas of the country. On behalf of the Ethiopian Government, I would like to express my deep appreciation to the partners accompanying us in the struggle to improve the lives of girls and boys in Ethiopia, in paving the way for a healthy and prosperous Ethiopia in the future.

\section{Ambassador Teshome Toga} Minister, Youth, Sports and Culture 


\section{TABLe of Contents}

Executive Summary ....................................................................... vii

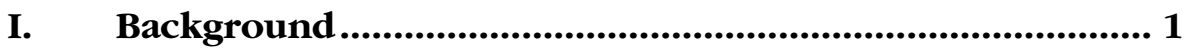

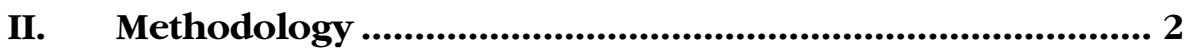

III. Sample Characteristics ..................................................... 4

IV. Parental Survivorship \& Presence .................................. 6

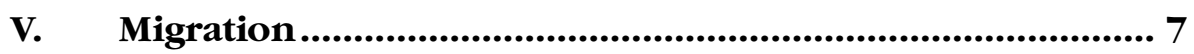

VI. Education \& Livelihoods ................................................. 10

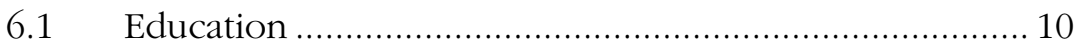

6.2 School and work ..................................................... 10

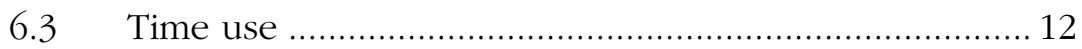

6.4 Female domestic workers/servants .............................. 13

6.5 Income, savings and spending …................................ 15

VII. Social Networks \& Sense of Well-Being ............................ 16

7.1 Friends and discussion topics ....................................... 16

7.2 Safety and well-being in the neighborhood ................... 16

VIII. Reproductive Health Knowledge \& Sexual

Behavior ......................................................................... 19

8.1 Reproductive health knowledge ................................. 19

8.2 Sexual behavior ............................................................ 19

8.3 Experience with HIV/AIDS .......................................... 20

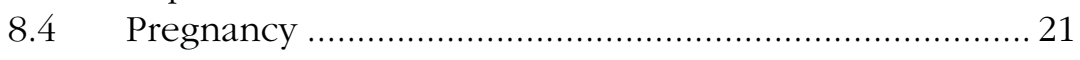

IX. Adolescent Reproductive Health Programs ...................... 22

X. Implications for Programs ............................................... 24

10.1 Recognize the diversity of young people ...................... 24

10.2 Recognize the additional vulnerability of subgroups of adolescents ............................................ 24

10.3 Design programs that are appropriate to the context of young lives .............................................. 24

10.4 Program content that acknowledges the complexity of young lives ........................................ 25

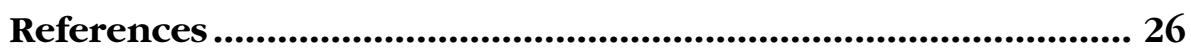




\section{TABLES \& Figures}

Table 1 Sample characteristics, by sex of the respondent. ............. 5

Table 2 Parental survivorship, parental residence, and

fostering experiences, by sex. ......................................... 6

Table 3 Characteristics of Addis Ababa natives and

in-migrants by sex .............................................................. 7

Table $4 \quad$ Reasons for migration, by sex. …........................................ 8

Table 5 Education, vocational training and literacy, by sex .......... 11

Table 6 Female domestic servants versus other females ................ 13

Table 7 Community support, perceptions of safety and experience of crime, by sex. ...................................... 17

Table 8 Reproductive health and HIV/AIDS knowledge,

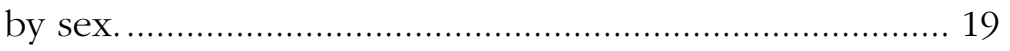

Table 9 Context of sexual activity, by sex. ................................ 20

Table 10 Profile of youth center and peer education programs in study area

Table 11 Percentage of adolescents utilizing youth centers and peer educators in the previous year, by sex and age group

Figure 1 School and work status by age group and sex $(n=1076)$

Figure 2 Time use by school status and sex. 12 


\section{ACKNOWLDEGEMENTS}

This study would not have been possible without the support and guidance of a great many institutions and individuals. We appreciate the support and assistance of the Ministry of Youth Sports and Culture, the Regional Youth Bureaus, and Kebele officials in facilitating our work. We gratefully acknowledge the support of UNICEF, Turner Foundation, and DfID in making this study possible. Thanks go to Judith Bruce and Lisa Bohmer for guidance during conceptualization of the study, to Assefa Hailemariam for assistance with training and data collection and to Lucy N'gan'ga for data management. We wish to thank Judith Bruce, Nicole Haberland, and Mirgissa Kaba for their thoughtful comments on earlier drafts of this report. Finally, we thank the young people themselves who were so giving of their time, ideas and experiences and from whom we have learned a great deal about what it is to be an adolescent in urban Ethiopia. 


\section{Executive Summary}

Little research has focused on adolescents' lives in the slums of African cities; conversely most research of young people has emphasized reproductive health and HIV but not given a broad understanding of what life is like for young people in Africa today. This study drew on data collected from over 1000 adolescent boys and girls aged 10 to 19 in the low income and slum areas of Addis Ababa. Adolescents were selected at random and interviewed on a range of topics, giving a representative picture of adolescent life in the slums. Girls in the sample, and indeed, those listed in the initial household listing, outnumbered boys, with considerably more girls having migrated into Addis Ababa than boys. One out of ten adolescents had lost both of their parents. Contrary to the popular belief that adolescents live with their parents, only a minority of young people in this study lived with two parents ( 35 percent of boys and 24 percent of girls). What contributed to this, in part, was the fact that many adolescents migrated into Addis Ababa especially during their early adolescent years. Many came looking for educational and work opportunities, but a significant number of girls (1 out of 5) came to escape early marriage in their rural homes. Migrant adolescents were significantly more likely to be out of school, and to be poor and working long hours, compared to adolescent natives of Addis Ababa.

How adolescents spend their time differed by gender and by school status. When young people leave school they begin to spend considerably more time on paid and unpaid work. Whether in or out of school, boys spend more time in recreational and social activities than do girls, while girls spend more time in unpaid domestic work. Among working girls, 60 percent were engaged as domestic workers. Domestic work involved very long hours (an average of 62 hours per week) and very low pay (an average of 56 Birr, or $\$ 6.50$ per month).

Girls have considerably fewer friends and far less social support than do boys. Girls report fewer friends and having fewer people to turn to in case they need assistance. At the same time, they are more likely to feel discomfort in their neighborhood, with many reporting being scared of some of their neighbors and having experienced harassment or sexual assault.

Young people have reasonably high knowledge of HIV/AIDS, with somewhat less understanding of STIs, condoms and the fertile period. Only a minority of young people have had sex but many have had negative experiences. Among the sexually experienced, one quarter of girls and 18 percent of boys were coerced into their first sex; and a considerable number of both boys and girls have had sex with a much older partner. While there are 14 youth programs (peer education and youth centers) operating in the study area, only a minority of young people have accessed them. Youth centers reached only 12 percent of adolescents and peer education reached 20 percent, with boys - especially older boys - more than twice as likely to have been reached compared to girls. 
The study highlighted the vulnerability of adolescents living in slum areas of Addis Ababa. Moreover, specific sub-groups of adolescents emerged as highly disadvantaged. A web of vulnerabilities characterized the lives of many girls in the sample. Girls were more likely to have migrated to the area than boys. Girls - especially those who had migrated - were more likely to live without their parents and were considerably poorer than others; and many girls were in lowly paid exploitive jobs, especially domestic work. While only one respondent admitted to being a sex worker, it is likely that many such vulnerable girls used sex work to supplement their meager pay.

As a result of this research, the Ministry of Youth Sports and Culture designed a program for young people in Addis Ababa. The program addresses the vulnerability and social isolation of young people by promoting single sex and age-specific safe spaces for girls and boys. The program will target especially vulnerable young people including those with no parents, younger youth, those with large workloads such as domestic workers, and isolated young people with few or no friends.

Research and programs for young people tend to homogenize the adolescent population into one genderless mass, with little regard to age or social context. Adolescents experience rapid and intense changes between the ages of 10 to 19 . The experience and needs of a 12-yearold girl are considerably different from an 18-year-old boy. Yet, few programs acknowledge those differences. Greater segmentation of the adolescent population is needed in the design and content of programs, as well as greater attention to the specific circumstances of young people in local settings, especially vulnerable, hard-to-reach sub-groups of adolescents. 


\section{BACKGROUND}

In the last decade there has been increased attention to adolescent ${ }^{1}$ reproductive health (ARH) in the developing world, partly due to the high rates of HIV infection in this population, as well as other negative reproductive health $(\mathrm{RH})$ outcomes. As a relatively new field, research on youth and adolescents is still evolving. By and large, public health research on adolescents has focused on RH knowledge and sexual behavior, and many studies have homogenized youth, some not making distinctions between boys and girls and others not differentiating between vulnerable subgroups. Indeed, the failure to differentiate between adolescent subgroups and take account of differing circumstances has been seen as one of the greatest shortcomings in the field (Bruce 2002, Rani and Lule 2004).

For increasing numbers of African adolescents, life in urban areas is, effectively, life in the slums. "Mega cities" such as Addis Ababa are increasingly home to large segments of developing countries' populations, including a significant proportion of adolescents. Africa's largest cities attract migrants from rural areas, especially those in search of educational and livelihood opportunities or those escaping negative experiences or poor standards in their home areas. Those who are economically active, especially adolescents and young men and women, increasingly dominate urban areas in Africa (Zulu et al 2000, APHRC 2002). There has been little understanding of life for adolescents in low income and slum areas of Addis Ababa or, indeed, other urban centers in Africa, where infrastructure and services cannot keep pace with growth (Brockerhof and Brennan 1999).

This study focuses on adolescents' life experiences in low income and slum areas of Addis Ababa. The study sought to gain the widest view of adolescent life possible, covering a range of topics beyond $\mathrm{RH}$, such as parental presence, migration, education and livelihoods, and social networks and well-being. Findings are meant to inform future development of programs for young people that take account of their real life conditions and address the realities of vulnerable sub-populations.
In Addis Ababa, there is clean water, all kinds of food, people get nutritious meals, and there is electricity. In the rural areas, they use lamps. But here, since there is brightness, I like it. (Female, age 14, in school, 5 years of education )

\footnotetext{
'The target age group for this study was those aged 10 to 19 , the age group commonly considered "adolescents." While we recognize that the terms "adolescents," "youth," and "young people," refer to slightly different age groups, we use the terms interchangeably in this report.
} 


\section{Methodology}

Data for this study is from a population based survey of adolescents aged 10 to 19 conducted in Addis Ababa, Ethiopia in early 2004. The survey took place in two urban areas of Addis Ababa, Merkato area (Kebele $\left.{ }^{2} 13\right)$ and Kazanchis (Kebele 10), which are among the city's poorest areas. The estimated population of these areas was 20,000 in Kebele 13 and 17,000 in Kebele 10. These are very densely populated areas with an average of 5.4 members per household. In the initial stages of the study, all households in the study area were listed, collecting basic demographic information on all members of the household, regardless of age. A household was considered eligible for survey if it had an adolescent member aged 10 to 19, regardless of marital status. Eligible households were entered into the computer and 1200 households were selected at random, 600 each in Mercato and Kazanchis. Where a household had more than one adolescent aged 10 to 19, a Kish grid ${ }^{3}$ (Kish 1965) was used to select just one adolescent.

The questionnaire used in the survey was a mostly close-ended, structured instrument. Topic areas covered in the questionnaire were wide ranging, including household composition and assets, education, time use, migration, attitudes and expectations, $\mathrm{RH}$ knowledge and practice, marriage, pregnancy and childbirth, and sexual activity. In addition, specific questions, especially those for which prior research was limited, were asked in an open-ended format. The questionnaire was translated into Amharic and back-translated to ensure accuracy.

Survey interviewers had prior interviewing experience and were selected to be young enough so as to make respondents comfortable. Interviewers were trained for one day prior to the initial household listing and for five days prior to the larger survey During the five-day training, interviewers reviewed the questionnaire item by item and engaged in practice and mock interviews. For open-ended questions, interviewers were trained to probe respondents and record the response verbatim. Toward the end of the training, interviewers practiced the questionnaire on adolescents who were recruited from outside the study area. Male interviewers interviewed male respondents while females interviewed female respondents. Interviewers paid up to three visits to locate and interview the sampled adolescent.

Informed consent was obtained from all respondents. In addition, informed consent was obtained from the parents or guardians of adolescents when they had resident parents or guardians. Supervisors checked all completed questionnaires for data quality and completeness. Data was entered using Epi-Info and later converted to SPSS ${ }^{4}$ for analysis. Direct quotes from open-ended questions were translated and typed into a Word file.

${ }^{2}$ Kebeles are the lowest administrative unit in Ethiopia.

${ }^{3} \mathrm{~A}$ Kish grid is a random number table that can be used as a method for selecting a respondent at random.

${ }^{4}$ Statistical Package for the Social Sciences, Ver. 10.0 
In addition to the survey, an inventory of available youth programs was undertaken in study kebeles as well as adjacent areas. Two program directories were reviewed that catalogued RH programs in Ethiopia and activities of non-governmental organizations in Ethiopia (CRDA, 2000, COFAP, 2002). In addition, Kebele chairpersons were consulted to understand the various youth programs that were operating in their respective jurisdictions.

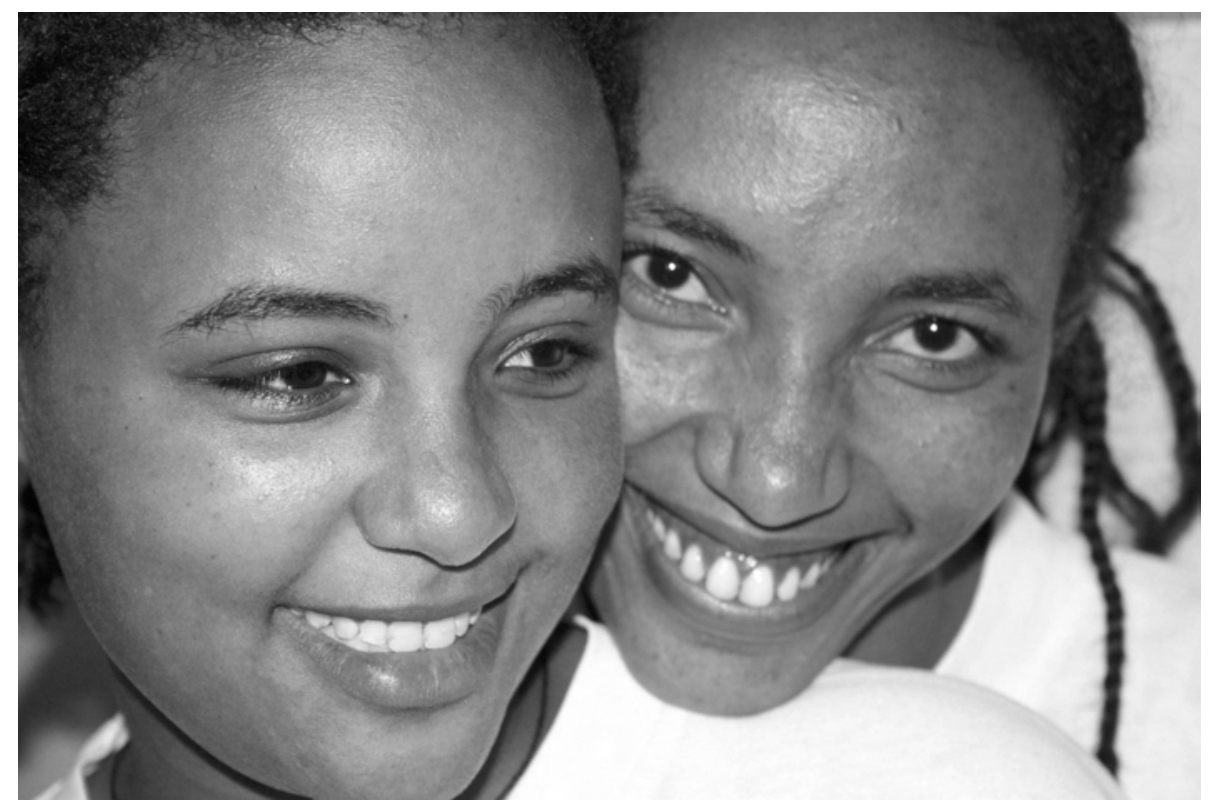

Living in this place is very difficult. The houses are built without spaces and there is violence. You go out in the morning peacefully and when you come back, muggers attack you... It is very scary after dark even when you are emptyhanded, let alone when you are holding money (Male, age 16, in school, 4 years education, never worked for pay) 


\section{Sample Characteristics}

A total of 1076 young people aged 10 to 19 were interviewed. The response rate for both boys and girls was 90 percent and did not differ by gender, which is consistent with or better than other surveys of adolescents using similar methods of data collection (see, for example, Ajayi et al, 1997). More girls than boys were interviewed and indeed, more girls than boys were recorded in the household listing. The excess of girls in these poor areas could be due to the greater number of female in-migrants into the area. ${ }^{5}$ Males and females in the sample did not differ in terms of age, school status or marital status. ${ }^{6}$ Boys had attained higher levels of education compared to girls, a finding consistent with educational data for Ethiopia generally (Population Council, 2002). Girls in the sample appeared to be poorer than boys, with significantly greater numbers of girls having five or fewer household amenities compared to boys. ${ }^{7}$ Finally, a significantly greater proportion of girls had migrated into Addis Ababa from other regions, compared to boys who are more likely to be native to Addis Ababa.

${ }^{5}$ In all 1350 girls were recorded in the household listing compared to 866 boys. The disparity in adolescent boys and girls could be due to the greater number of girls migrating into the area compared to boys. Forty-three percent of sampled girls had migrated into Addis Ababa, compared to 29 percent of boys, a difference that was statistically significant. Another contributing factor could be the tendency for boys to live on the street and therefore not be listed as a household member, while girls are more likely to be resident in households.

${ }^{6}$ Rates of marriage in this survey are similar to DHS results. Eight percent of Addis Ababa girls aged 15 to 19 interviewed in the DHS (2000) are ever married compared to 3 percent of girls aged 15 to 19 in the present survey.

7n order to measure socio-economic status, respondents were read a list of 15 items or amenities, adapted from the Ethiopia Demographic and Health Survey (2000). Respondents were scored as to the number of items that their household possessed, with possible scores ranging from 0 to 15 . 
Table 1: Sample characteristics, by sex of respondent

\begin{tabular}{|c|c|c|c|}
\hline Variables & Response categories & Boys $(n=400)$ & Girls $(n=676)$ \\
\hline \multirow[t]{2}{*}{ Age category } & 10 to 14 & 42.0 & 37.6 \\
\hline & 15 to 19 & 58.0 & 62.4 \\
\hline \multirow[t]{2}{*}{ School status } & In school & 77.0 & 71.7 \\
\hline & Out of school & 23.0 & 28.3 \\
\hline \multirow[t]{3}{*}{ Educational attainment } & No education & 1.8 & $9.8^{* * *}$ \\
\hline & 1 to 8 years & 76.0 & 71.3 \\
\hline & 9 or more years & 22.2 & 18.9 \\
\hline \multirow[t]{2}{*}{ Marital status } & Never married & 98.9 & 97.6 \\
\hline & Ever married & 1.1 & 2.4 \\
\hline \multirow[t]{5}{*}{ Ethnicity } & Amhara & 50.0 & $58.7^{* * *}$ \\
\hline & Oromo & 14.3 & 17.0 \\
\hline & Tigray & 7.2 & 5.0 \\
\hline & Gurage & 24.3 & 18.3 \\
\hline & Other & 4.2 & 1.0 \\
\hline \multirow[t]{4}{*}{ Religion } & Orthodox & 74.3 & $82.0^{* *}$ \\
\hline & Protestant/Other Christian & 3.3 & 5.0 \\
\hline & Muslim & 21.8 & 12.6 \\
\hline & Other & 0.6 & 0.4 \\
\hline \multirow[t]{2}{*}{ Socio-economic index } & 0 to 5 household assets & 25.5 & $39.2^{* * *}$ \\
\hline & 6 to 15 household assets & 74.5 & 60.8 \\
\hline \multirow[t]{2}{*}{ Area of residence } & Mercato (Kebele 13) & 58.8 & 45.1 \\
\hline & Kazanchis (Kebele 10) & 41.2 & $54.9^{* * *}$ \\
\hline \multirow[t]{2}{*}{ Migrated into Addis } & Yes & 29.2 & $43.1^{* * *}$ \\
\hline & No & 70.8 & 56.9 \\
\hline
\end{tabular}

Differences between groups significant at ${ }^{*} p<0.05 ;{ }^{* *} p<0.01 ;{ }^{* * *} p<0.001$ 


\section{Parental Survivorshit \& Presence}

My mother got sick and I came along with her when she came for medical treatment. But she died. So I stayed here with my uncle. Since my father was sick too, I didn't want to go back to the rural area and trouble him. (Female, age 10, migrated to Addis Ababa from Amhara at age 5, in school, 1 year of education)
For one out of ten adolescents surveyed, both of their parents were dead (Table 2). Many of these young people could be AIDS orphans though, given the stigma and misconceptions surrounding the disease, young people may not want to admit or may not know that they lost their parents to AIDS. ${ }^{8}$ Sixty percent of adolescents reported that both their parents were alive.

Programmers and policymakers often assume that young people are living with their parents. Contrary to this popular assumption, a considerable number of slum-dwelling adolescents were not living with parents, with more girls living on their own, compared to boys. Fully 51 percent of adolescent girls living in slum areas are living with neither parent compared to 29 percent of boys. Girls not living with their parents is likely related to the fact that they are significantly more likely to be fostered ( 37 percent) and significantly more likely to have migrated from other regions (43 percent), compared to boys.

Table 2: Parental survivorship, parental residence, and fostering experiences, by sex

\begin{tabular}{llcc}
\hline Variable & Response category & Boys (n=400) & Girls (n=676) \\
\hline Parental Survival & Both parents alive & 60.8 & 59.2 \\
& One parent dead & 28.6 & 32.0 \\
& Both parents dead & 10.6 & 8.8 \\
Living Arrangements & Both parents & 34.8 & $24.0^{* * *}$ \\
& Mother only & 29.3 & 21.5 \\
& Father only & 7.0 & 3.4 \\
Ever Fostered & No parents & 28.9 & 51.1 \\
& Yes & 24.7 & $36.7^{* * *}$ \\
& No & 75.3 & 63.3 \\
\hline
\end{tabular}

Differences between groups significant at ${ }^{*} p<0.05 ;{ }^{* *} p<0.01 ;{ }^{* *} p<0.001$

${ }^{8}$ Only 10 respondents reported that they had lost a parent to AIDS 


\section{Migration}

Over one third of the sample migrated into Addis Ababa from other regions, with far more girls ( 43 percent) having migrated than boys (29 percent). The experience of adolescents who are native to Addis Ababa versus that of migrants appears to be very divergent, especially for girls (Table 3).

Table 3: Characteristics of Addis Ababa natives and in-migrants, by sex

\begin{tabular}{|c|c|c|c|c|c|}
\hline \multirow[b]{2}{*}{ Variable } & \multirow[b]{2}{*}{$\begin{array}{l}\text { Response } \\
\text { category }\end{array}$} & \multicolumn{2}{|c|}{ Boys } & \multicolumn{2}{|c|}{ Girls } \\
\hline & & $\begin{array}{l}\text { Native } \\
(\mathrm{n}=264)\end{array}$ & $\begin{array}{l}\text { Migrant } \\
(n=105)\end{array}$ & $\begin{array}{l}\text { Native } \\
(\mathrm{n}=347)\end{array}$ & $\begin{array}{l}\text { Migrant } \\
(n=261)\end{array}$ \\
\hline \multirow[t]{2}{*}{ Age category } & 10 to 14 & 44.3 & 38.1 & 40.9 & $33.0^{*}$ \\
\hline & 15 to 19 & 55.7 & 61.9 & 59.1 & 67.0 \\
\hline \multirow[t]{2}{*}{ School status } & In school & 78.8 & 77.1 & 76.1 & $64.8^{\star *}$ \\
\hline & Out of school & 21.2 & 22.9 & 23.9 & 35.2 \\
\hline \multirow[t]{3}{*}{ Educational attainment } & No education & 1.5 & 1.9 & 6.4 & $14.8^{* * *}$ \\
\hline & 1 to 8 years & 75.3 & 77.7 & 70.6 & 72.4 \\
\hline & 9 or more years & 23.2 & 20.4 & 23.0 & 12.8 \\
\hline \multirow[t]{2}{*}{ Living arrangements } & Lives with 1 or 2 parents & 77.7 & 55.2 & 63.4 & 31.9 \\
\hline & Lives with no parents & 22.3 & $44.8^{\star \star \star}$ & 36.6 & $68.1^{* * *}$ \\
\hline \multirow[t]{4}{*}{ Parental survivorship } & Father alive & 65.4 & 73.5 & 64.2 & $72.5^{*}$ \\
\hline & Father dead & 34.6 & 26.5 & 35.8 & 27.5 \\
\hline & Mother alive & 82.9 & 84.5 & 80.9 & 85.0 \\
\hline & Mother dead & 17.1 & 15.5 & 19.1 & 15.0 \\
\hline \multirow[t]{2}{*}{ Ever worked for pay } & Yes & 17.8 & $33.3^{\star *}$ & 10.1 & $38.1^{* * *}$ \\
\hline & No & 82.2 & 66.7 & 89.9 & 61.9 \\
\hline \multirow[t]{2}{*}{ Marital status } & Ever married & 1.6 & 0.0 & 1.5 & 3.9 \\
\hline & Never married & 98.4 & 100.0 & 98.5 & 96.1 \\
\hline \multirow[t]{2}{*}{ Threatened marriage } & Yes & 1.5 & $10.5^{\star \star *}$ & 4.1 & $25.2^{* \star *}$ \\
\hline & No & 98.5 & 89.5 & 95.9 & 74.8 \\
\hline
\end{tabular}

Differences between groups significant at ${ }^{*} p<0.05 ;{ }^{* *} p<0.01 ;{ }^{* * *} p<0.001$

Both male and female migrants were significantly less likely to live with their parents compared to Addis Ababa natives. These differences did not appear to be related to parental survivorship, as a greater proportion of migrants' parents were alive, compared to natives' parents. Among girls, migrants were significantly less likely to be in school ( 65 percent of migrants versus 76 percent of non-migrants) and significantly more likely to have never attended school (15 percent of migrants versus 6 percent of non-migrants). Migrants are more likely to be working than nonmigrants. 
While there were very few adolescents in the sample who had ever been married, migrant girls were slightly more likely to have been married at one time compared to Addis Ababa natives, a difference that was marginally significant at $\mathrm{p}<0.10$. Among the ever married in-migrants, half of the girls were divorced which undoubtedly contributed to their moving to Addis Ababa. Ethiopia has one of the highest rates of divorce in the world and a substantial numbers of adolescents are already divorced (Tilsen and Larsen, 2000). It is likely that girls who moved to Addis Ababa following a divorce in their rural homes may underreport previous marriages, preferring to describe themselves as never-married, thereby allowing them to 'make a fresh start' in Addis Ababa.

The majority of adolescent migrants ( 47 percent) came to Addis Ababa during early adolescence, age 10 to 14 . The majority of boys migrated with their parents, especially when they migrated at an early age. Interestingly, girls tend not to migrate with their parents, but came with other relatives or non-relatives. While 67 percent of boys who migrated before age 10 came with their parents, only 35 percent of girls who migrated before age ten came with parents. Among young people who migrated between the ages of 10 to 14,48 percent of boys moved with their parents compared to only 24 percent of girls. One reason for these differences could be boys and girls reasons for migration.

Table 4 displays adolescents' motivations for migration. Percentages in the table sum to over 100 as more than one reason may have been mentioned, reflecting that causes for migration were often complex and interlinked. For example, young people mentioned lack of schools, leading parents to arrange marriages for their daughters, leading to girls migrating to escape marriage.

For both boys and girls, educational opportunities in Addis Ababa were the most frequently mentioned reasons for migration. Many mentioned the absence of schools in their places of origin, especially schools at the upper levels, while others mentioned that their local schools taught in a language that was foreign to them. While many young people described

Table 4: Reasons for migration*, by sex

\begin{tabular}{lcc}
\hline Reason given & Boys $(\mathbf{n}=\mathbf{9 4})$ & Girls $(\mathbf{n}=\mathbf{3 0 6})$ \\
\hline Educational opportunities & 41.5 & 43.9 \\
Work opportunities & 25.5 & 25.5 \\
Poverty in the rural area & 20.2 & 22.1 \\
Family problems & 26.5 & 18.6 \\
Threat of marriage & 1.1 & 18.6 \\
Joining family members & 24.5 & 24.1 \\
\hline
\end{tabular}

*Percentages may sum to over 100 as more than one reason was possible 
that they came to the capital for the educational opportunities, not all entered school. Some were disappointed by promises of school that were never fulfilled and others simply had aspirations to attend school, but did not attend.

Work opportunities in Addis Ababa were also cited as reasons for moving from rural areas, especially where families could not support children. A considerable number of girls moved to Addis Ababa when they were promised jobs as domestic workers:

Since my parents were not able to educate me and raise me, I came [to Addis Ababa] to work as a domestic worker. When I was there [in the rural area], I used to herd cattle for people and since life didn't go well for me and since they made me do things that were too much for me, I came to Addis Ababa to work as a domestic worker. (Age 10, Migrated from Ambara Region at age 9, working as domestic worker, never been to school)

In fact, 25 percent of the female migrant sample were domestic workers, compared to less than one percent of the non-migrant sample.

Impending or threatened forced marriage was a significant reason why girls came to Addis Ababa, but it was not a reason given by boys. ' Many girls did not want to be forced into marriage and so ran away to Addis Ababa. Such girls are effectively 'refugees from marriage' and this pattern could account for the low number of girls migrating with parents, and the large number migrating during early adolescence, the time when many girls' marriages are arranged.

My parents were trying to marry me, but I didn't want to get married. So I ran away and came here. My mother has said that I'm not her daughter any more, but I didn't want to get married. I wanted to study - that's why I came. (Age 17, Migrated from Ambara Region at age 11, 5 years education, in school)

When I was there since there was a tradition of early marriage, the neighbors and relatives were nagging my father to get me married. So I came here to live with other relatives. I will start school next year. (Age 13, Migrated from Oromiya Region at age 12, never attended school, never worked for pay)

Most girls who fled early marriage in the rural areas ended up alone, without family members in Addis Ababa. Ninety one percent of girls who migrated to escape marriage live with neither of their parents.
My parents were trying to marry me, but I didn't want to get married. So I ran away and came here. My mother has said that I'm not her daughter any more, but I didn't want to get married. I wanted to study that's why I came. (Age 17, Migrated from Amhara Region at age 11, 5 years education, in school)

'Only one boy mentioned impending marriage as reason 


\section{Education \& Livelihoods}

\subsection{Education}

The disadvantage that Ethiopian girls face in education seems to hold true for adolescents in low income and slum areas of Addis Ababa. Girls are significantly less likely to have ever been to school and less likely to have received vocational training (Table 5). When they do start school, they start at a later age than boys, almost one year later. Among the out of school, they have an average of two years less education than do boys. As a result, they are significantly more likely to be illiterate. Notably, many girls and boys do not reach secondary education, the level where many organizations operate RH and HIV programs for young people.

\subsection{School and work}

Figure 1 shows the school/work status of young people by sex and age group and how the school work status of adolescents changes rapidly from early to late adolescence. In early adolescence (age 10 to 13), the vast majority of both boys and girls in Addis Ababa are in school, though disparities do exist between them. During ages 14 to 16, adolescents begin to change their status, though the changes are more apparent for girls than for boys. By middle adolescence, more girls have begun working for pay and a considerable number are "idle", or out of school and not working. By late adolescence, school attendance has dropped for both boys and girls and a considerable proportion of young people are neither in school nor working.

Among adolescents who were working for pay, the pattern of paid work differed markedly for boys compared to girls. Among working girls, the majority were employed as domestic servants (60 percent), followed by casual laborers (11 percent) and waitresses ( 9 percent). Boys were involved in a wider array of activities including daily manual laborer (20 percent), cleaner (17 percent), tradesman (17 percent), and shoe shine (13 percent). 
Table 5: Education, vocational training and literacy, by sex

\begin{tabular}{|c|c|c|}
\hline Variables & Boys $(n=400)$ & Girls $(n=676)$ \\
\hline \multicolumn{3}{|l|}{ Ever attended school } \\
\hline Yes & 98.2 & 90.4 \\
\hline No & 1.8 & $9.6^{* * *}$ \\
\hline Mean age of entry into school & 7.0 & $7.9^{* * *}$ \\
\hline Mean age left school & 14.9 & 15.3 \\
\hline Mean years of education (out of school only) & $6.9^{* * *}$ & 4.7 \\
\hline Received vocational training & $14.8^{*}$ & 10.4 \\
\hline \multicolumn{3}{|l|}{ Literacy level } \\
\hline Reads easily & 76.8 & 68.2 \\
\hline With difficulty & 20.4 & 18.2 \\
\hline Not at all & 2.8 & $13.6^{* * *}$ \\
\hline
\end{tabular}

Differences between groups significant at ${ }^{*} p<0.05 ;{ }^{* *} p<0.01 ;{ }^{* * *} p<0.001$

Young people talked about good and bad experiences at work.

What is nice is that a job connects you with people. And those people help you through difficult times. (Female age 18, Addis Ababa native, out of school, 7 year education, not currently working)

There are some [employers] who make me do the job without paying me; there are some who simply shout at you whether it's your fault or not; and there are some who don't support you when you get sick. (Female, age 16, migrated from Ambara at age 8, working as domestic servant)

Figure 1. School and work status, by age group \& sex $(n=1076)$

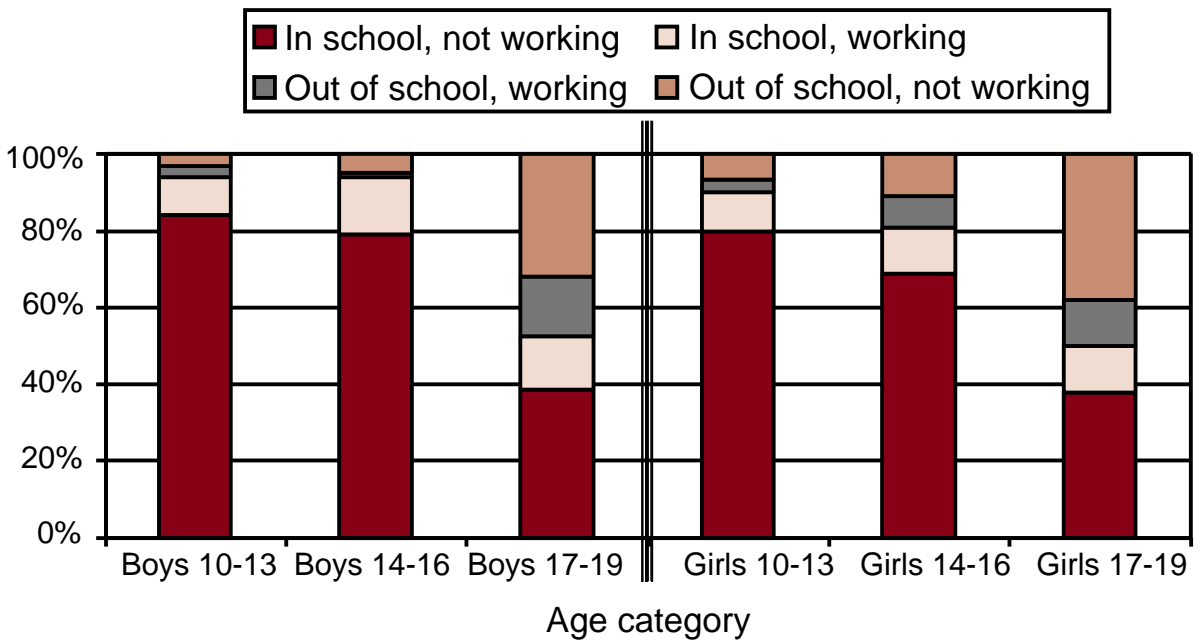


Many adolescents, especially girls, talked about being exploited by employers:

I hate my job when I get refused my salary and when they [employers] want me for sex. (Female, age 19, migrated from SNNP at age 19, 7 years of education, makes handicrafts)

Negative experiences were especially common among young people working in fields where they are easily exploited, such as domestic workers for females and shoe shine boys for males.

\subsection{Time use}

How young people spend their time differs substantially by sex and whether or not they are in school (Figure 2). When young people are in school, the largest part of their day is spent in school. However time outside school is quite different for boys compared to girls. Boys spend significantly more time in recreation and socializing (mean 31 percent of day), while girls spend their out of school time in domestic duties (mean 19 percent). When young people leave school, the way they use their time diverges even more. Girls devote a significant amount of time to paid and unpaid work (29 percent and 33 percent respectively) while boys engage in paid work and recreation (33 percent and 38 percent respectively). One large subgroup of girls are domestic servants, who devote more than 50 percent of their waking hours to paid work and an additional 18 percent to unpaid work.

Figure 2. Time use, by school status and sex

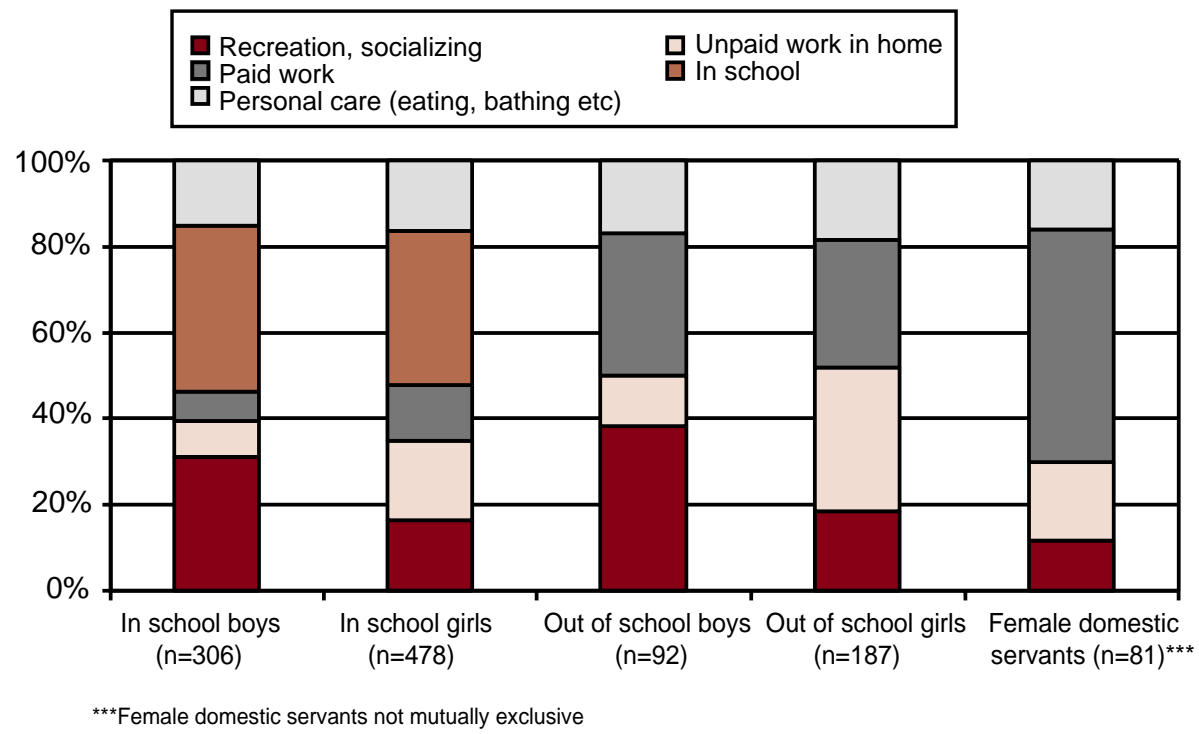




\subsection{Female domestic workers/ servants}

Twelve percent of girls in the sample were domestic workers. Over 60 percent of working girls were domestic workers, underscoring how such work absorbs a large segment of the adolescent female labor force. Domestic workers work long hours for low pay, reporting they work an average of 62 hours per week, for an average pay of 14 Birr (\$1.60) per week, or about 56 Birr (\$6.50) per month (see Income, savings and spending). Girls who are working in domestic service are, indeed highly vulnerable and isolated compared to other girls.

Table 6: Female domestic servants versus non-domestic servants

\begin{tabular}{llcc}
\hline Variable & $\begin{array}{l}\text { Response } \\
\text { categories }\end{array}$ & $\begin{array}{l}\text { Female non-domestic } \\
\text { worker }(\mathrm{n}=81)\end{array}$ & $\begin{array}{c}\text { Female domestic } \\
\text { worker }(\mathrm{n}=594)\end{array}$ \\
\hline Educational attainment & None & 8.0 & $22.2^{* * *}$ \\
& $\begin{array}{l}\text { 1 to 8 years } \\
\text { 9+ years }\end{array}$ & 71.3 & 71.6 \\
& & 20.7 & 6.2 \\
Lives with at least 1 parent & & 54.4 & $19.8^{* * *}$ \\
Migrated from another region & & 35.1 & $96.3^{* * *}$ \\
& & & 0.0 \\
Region of origin & Tigray & 6.3 & 56.4 \\
& Amhara & 44.7 & 28.2 \\
& Oromiya & 26.8 & 12.8 \\
Been pressured to marry & SNNP & 20.0 & 2.6 \\
Have many friends & Other & 2.1 & $41.0^{* * *}$ \\
\hline
\end{tabular}

Differences between groups significant at ${ }^{*} p<0.05 ;{ }^{* *} p<0.01 ;{ }^{* * *} p<0.001$

Domestic servants are significantly more likely to have no education compared to those who are not in domestic work. The vast majority of domestic servants (96 percent) have migrated from another region, and perhaps for this reason, most are not living with parents. Domestic workers are more likely to be from Amhara region which is a source of many in-migrants into Addis Ababa. Presumably, many of the girls have migrated to escape early marriage, with a significant number citing pressure on them for marriage. Probably because of extremely long work hours, domestic workers have few friends and social connections. Only 14 percent agreed with the statement that they have many friends. 


\subsection{Income, savings, and spending}

Among those in paid work, both boys and girls worked very long hours. However, working girls were earning considerably less than boys, despite working much longer hours. Girls worked an average of 57 hours per week ( 62 hours among domestic workers), compared to boys' 46 hours, a difference that was statistically significant. On average, girls were earning 21 Birr (US\$2.40) per week, compared to boys' 36 Birr (US\$4.20) per week. One reason for differences in pay could be the type of work that girls were involved in. The majority of girls were engaged in domestic work and, on average, these girls only earned 14 Birr (US\$1.60) per week. In addition, more boys than girls were self employed (18 percent of boys and 6 percent of girls) with self employment more likely to be better paid than working for others.

For the most part, young people retained control of their income, with 92 percent of working boys and 89 percent of working girls reporting that they are able to decide how their money is spent. At the same time, their income was shared with others, with 64 percent of working adolescent boys and girls reporting that they give some of their money to others. The vast majority of earners mentioned spending their money on food and clothing for themselves and their families. Significantly more girls than boys reported sending money home to their parents (39 percent of girls; 21 percent of boys).

Nine percent of boys and 10 percent of girls have savings. However, boys had saved much more than girls, with boys averaging 550 Birr (US\$64) to girls' 200 Birr (US\$23). Boys tend to keep their savings at home (78 percent) while girls save both at home (54 percent) or with friends and relatives ( 33 percent). The most common reasons for saving was to purchase personal items for oneself ( 42 percent of boys and 59 percent of girls), for medical emergencies (22 percent of boys and 49 percent of girls) and for education (19 percent of boys and 36 percent of girls).
Most of the time, the child of the employers beats me without having a reason. When I ask him why he does that, he beats me again. (Female, age 14, migrated from SNNP at age 5, 2 years education, works as domestic worker) 
Boys insult, beat and hassle girls on the streets and people do not try to intervene when girls get beaten up on the streets.

(Female, age 14, native of Addis Ababa, in school, 8 years of education)

\section{Social Networks \& Sense of Well- BEING}

Recent studies have underscored the importance of social connections and supportive relationships in promoting adolescent well-being, including positive RH outcomes (Jessor et al 1998, Resnick et al 1997, Karim et al 2003) The poverty and insecurity of low income and slum areas makes social support networks that much more critical in the lives of young people. We asked a series of questions to assess the nature of social support mechanisms available to adolescents as well as their experience in the community.

\subsection{Friends and discussion topics}

Girls report having significantly fewer friends than do boys. Fourteen percent of girls say that they have no friends, compared to 4 percent of boys. Overall, girls report an average of 2.7 friends compared to boys 4.7 friends. While girls have fewer friends, their relationships seem to be more intimate. We read a list of subjects that one might discuss with one's friend and asked respondents if they had discussed the topic with their closest friend. Topics included, future goals, financial problems, people who tease or bother you, money you have saved or earned, HIV/ AIDS, sexually transmitted infections, family planning, condoms, violence in the neighborhood and the ideal marriage. For every subject mentioned, girls were significantly more likely to have discussed with their closest friend compared to boys.

\subsection{Safety and well-being in the neighborhood}

Young people were asked a series of questions related to their support in the community, their feelings of safety, and experience of crime and violence in the neighborhood (Table 7). On nearly all issues covered, the experience of girls differed significantly than boys. Boys reported far greater social support mechanisms in their neighborhood including having many friends, having a place to stay if they needed it, and having someone from whom they could borrow money. On the other hand, girls were significantly more likely to feel insecure in their neighborhood and to have experienced harassment. Two thirds of girls reported they are scared of someone in their neighborhood and over half are scared of being raped. This is perhaps not surprising as one third of girls report that they have been groped and nearly half report teasing and harassment.

When young people talked about their experience in their neighborhood, they often talked about crime, harassment, and pollution.

I hate it when children get raped, when they get beaten up and are forced to do things that are beyond their capabilities and cause them physical disability. And there are some people who would steal children away from their parents and use them for begging, they'd also make them prostitutes and use them as their means of income... All this terrifies me. (Female age 12, migrated from Oromiya at age 10, in school, 1 year of education) 
Boys insult, beat and hassle girls on the streets and people do not try to intervene when girls get beaten up on the streets. (Female, age 14, native of Addis Ababa, in school, 8 years of education)

Boys in particular mentioned gang fights and drugs:

There are gang fights and sometimes you can get hurt in the middle of them. There are many 'chat' and 'shisha' houses and there is too much dirt in our area so we are exposed to diseases. (Male age 10, migrated from Ambara at age 9, in school, 1 year of education)

Table 7: Community support, perceptions of safety and experience of crime, by sex

\begin{tabular}{lcc}
\hline Statement & Boys & $\begin{array}{c}\text { Girls } \\
(n=400)\end{array}$ \\
$(n=676)$
\end{tabular}

\section{Experience of social support in the neighborhood}

You have many friends in the neighborhood $59.0^{* \star *}$

If you didn't have a place to sleep, there is someone in your neighborhood who would take you in

If you needed money urgently, there is someone in your neighborhood who you could borrow from

You have a place in the neighborhood (other than home or school) to meet your same sex friends

\section{Feelings of well-being and comfort in the neighborhood}

You don't feel comfortable walking in your neighborhood after dark

You know of girls in your neighborhood who have been raped

You are scared of being beaten by someone in your neighborhood

You are scared of some people in your neighborhood

At times you are scared that you will be raped in your neighborhood

\section{Experience of harassment and crime}

You have been groped by someone of the opposite sex in your neighborhood 
In addition, girls' self-esteem and feelings of self worth appeared to be lower than boys. Thirty-three percent of girls disagreed with the statement, "you feel as intelligent as most of the young people your age," compared to 18 percent of boys. Likewise, 36 percent of girls agreed with the statement, "You sometimes feel you are worthless," compared to 24 percent of boys.

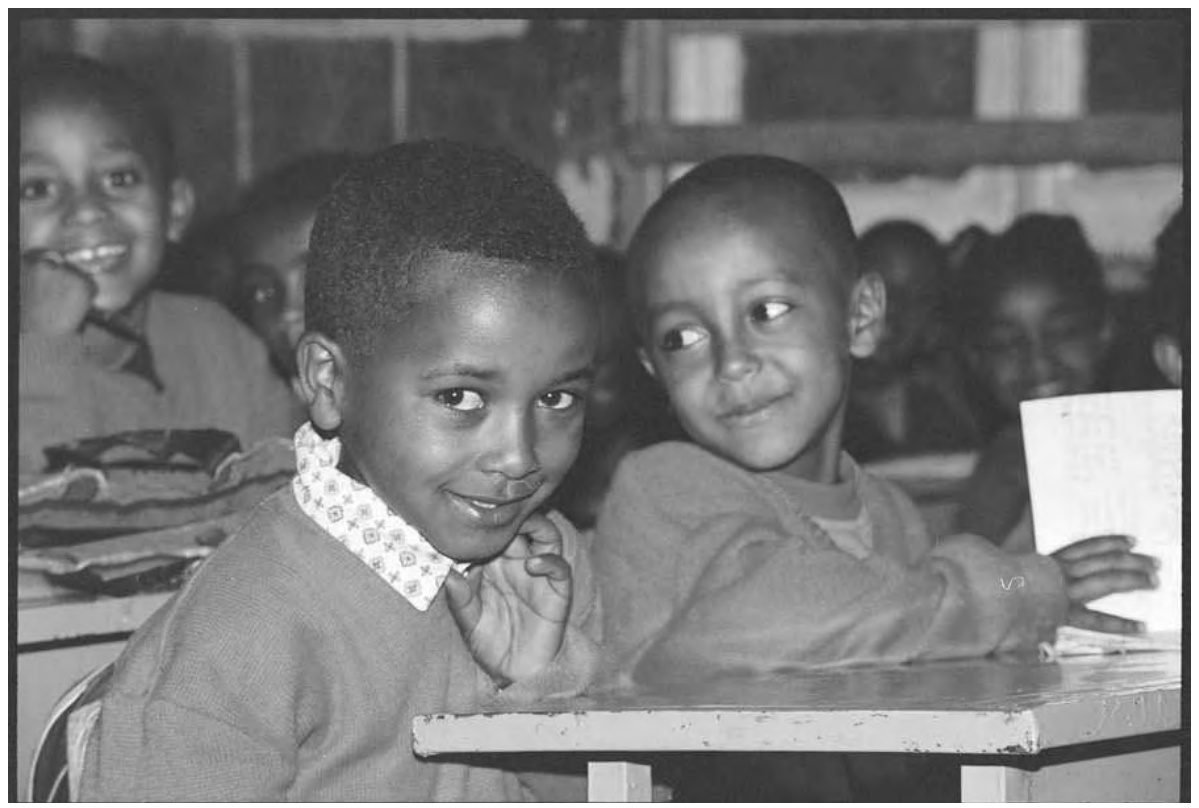




\section{Reproductive Health Knowledge \& Sexual Behaviour}

\subsection{Reproductive health knowledge}

Young people surveyed were fairly knowledgeable on most issues related to RH and HIV/AIDS and knowledge did not differ significantly between males and females. The vast majority of respondents knew that there was no cure for AIDS, that a healthy looking person can have HIV, and that HIV infection is not confined to big cities and towns. A surprising proportion of respondents ( 23 percent) felt that most HIV infection is from accidents from sharp objects, which is perhaps a result of programs over-emphasizing this mode of infection and avoiding discussions of sex. Areas where knowledge was weakest was in terms of the fertile period in the girl's cycle, recognizing that STIs can be asymptomatic, and the fact that withdrawal is not protective of HIV infection.

\subsection{Sexual behavior among unmarried adolescents}

Among unmarried young people in the sample, 8 percent of boys and 9 percent of girls are sexually experienced. On average, the partners of both boys and girls were older than themselves, a pattern that is common for girls but not for boys. Girls' first sex partners were on average five years older than themselves while boys' first partners were two years older. One quarter of girls and 18 percent of boys were coerced into first sex either through pressure, threats, physical force or the promise of money or gifts.

Table 8: Reproductive health and HIVIAIDS knowledge, by sex

\begin{tabular}{lcc}
\hline & Boys ( $\mathbf{n = 4 0 0 )}$ & Girls ( $\mathbf{n}=\mathbf{6 7 6})$ \\
\hline Know the fertile period of a girl's cycle & 24.8 & 27.9 \\
Know that a woman cannot always tell is she has an STI & 35.9 & 33.6 \\
Know that a condom cannot get lost in a woman's body & 56.3 & 48.2 \\
Know that if a man pulls out before ejaculation, the girls can still get HIV & 51.6 & 50.7 \\
Know that condoms are effective in preventing HIV infection & 71.9 & 70.4 \\
Know that a woman cannot always tell if a man has an STI & 67.1 & 71.7 \\
Know that most people do not get HIV from sharp objects & 75.2 & 76.5 \\
Know that HIVIAIDS is not only contracted in big towns & 76.9 & 82.1 \\
Know that there is no cure for AIDS & 88.6 & 84.8 \\
Know that a healthy looking person can have HIV & 94.3 & 96.0 \\
\hline
\end{tabular}

Differences between groups significant at ${ }^{*} p<0.05 ;{ }^{* *} p<0.01 ;{ }^{* *} p<0.001$ 
Sex among unmarried adolescents is indeed sporadic with only 45 percent of sexually active adolescents having had sex in the last month. Most young people have had one or two lifetime partners, with the mean number of sex partners being 1.7 for both boys and girls. Among the sexually experienced, 65 percent of boys and 54 percent of girls have used a condom. However, condom use is not consistent, with only half of ever users using it consistently during their last five acts of intercourse.

The sexual experience of young people is often not within their control, with many not able to refuse sex or not able to use a condom when they want to (Table 9).

Table 9: Context of sexual activity among unmarried adolescents, by sex

\begin{tabular}{lcc}
\hline & Boys ( $\mathbf{n}=\mathbf{3 5})$ & Girls ( $=\mathbf{5 6})$ \\
\hline Coerced at first sex & 17.6 & 24.6 \\
Have not always been able to use a condom when wanted & 8.6 & 21.4 \\
Have had sex with a partner 10+ years older & 20.0 & 23.2 \\
Had sex because they thought they would get money & 8.6 & 8.9 \\
Had sex at times when they did not want to & 17.1 & 32.1 \\
\hline
\end{tabular}

Differences between groups significant at ${ }^{*} p<0.05 ;{ }^{* *} p<0.01 ;{ }^{* * *} p<0.001$ 


\subsection{Experience with HIV/AIDS}

Thirty-six percent of young people know someone who is suffering from or has died of HIV/AIDS. Most respondents report that their relationship to the AIDS victim was as acquaintance or neighbor, while seven percent of young people say that they have a family member who has been infected with or died of HIV/AIDS. HIV/AIDS does seem to be an important factor in the lives and experience of young people:

HIV/AIDS is spreading fast and people infected with the disease do many bad things to get even with people. The residents of Addis Ababa and some house renters discriminate against those who are infected. (Female, age 15, Addis Ababa native, in school, 7 years of education)

Many young people drink alcohol. They are very naughty and they hassle people on the streets. And also, many people are being infected with AIDS. When I see this, I wish I had not come here. It's bad. (Female, age 19, migrated from Ambara at age 19, 10 years education, not working)

Fully 11 percent of girls and 5 percent of boys worry that they may be HIV positive. Nearly 40 percent of sexually experienced young people have the same worry. Many young people report wanting to undergo voluntary counseling and testing (VCT), with 62 percent of young people saying that they would like to be tested, and 73 percent saying they know where they can get the test. Still, few report having had the test ( 7 percent) suggesting that there may be other barriers to being tested, such as cost or accessibility.

\subsection{Pregnancy}

Only 16 girls in the sample had given birth and five boys admitted to having caused a pregnancy. Among the girls, none (including the married girls) wanted the pregnancy at that time and would have preferred to have waited. Three girls in the sample admitted that they had induced abortion.

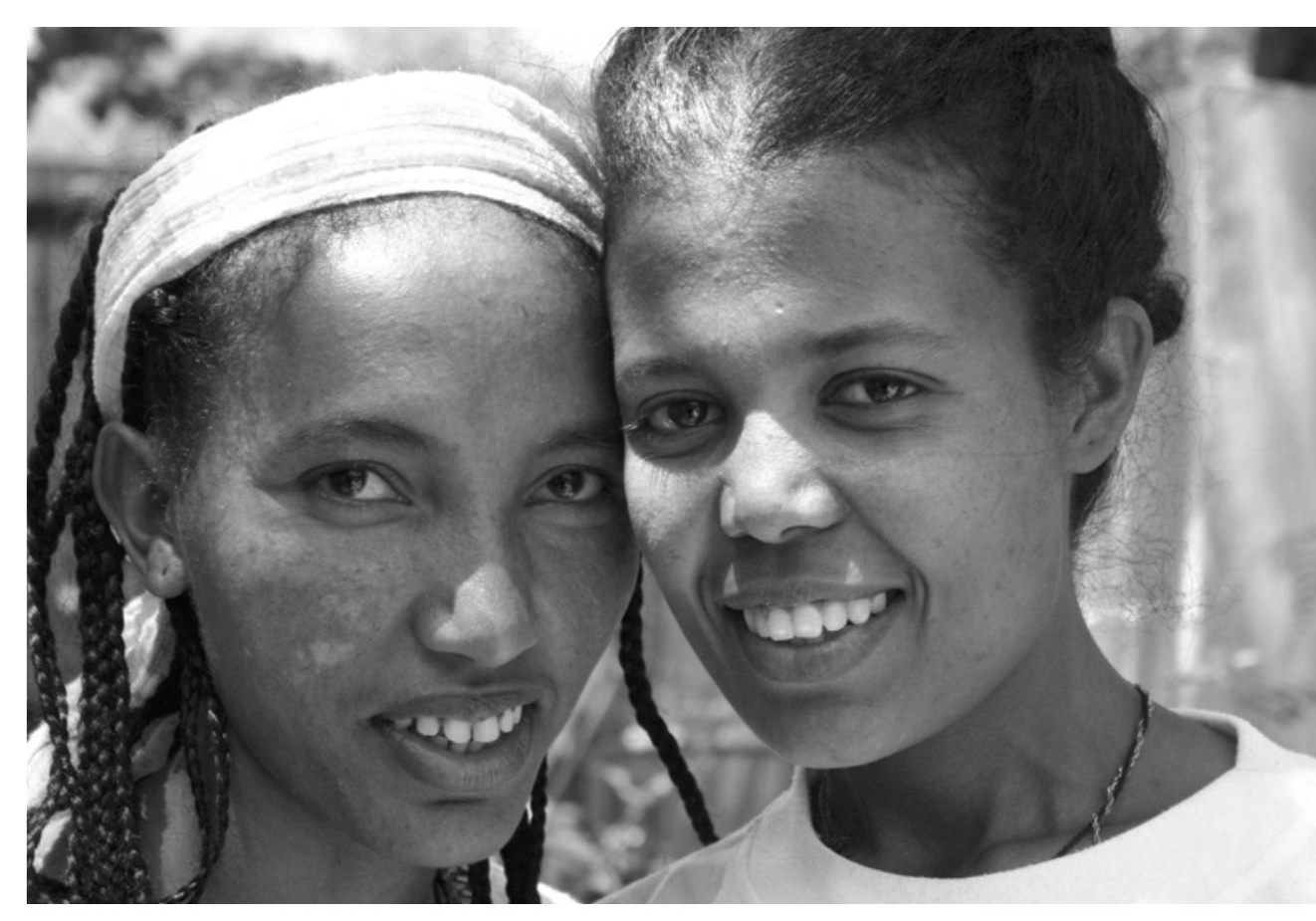


Many things have been said and have been told about HIV/AIDS. But, it's very sad that it has not been practical. (Female age 10, Addis Ababa native, in school, 4 years of education)

\section{Adolescent Reproductive Health Programs}

Government and nongovernmental organizations in Ethiopia have made considerable investments in RH programs for young people, especially in urban areas. Two program models have been particularly popular, youth centers and peer education. This study sought to understand young people's utilization of existing adolescent $\mathrm{RH}$ programs. There are six youth centers and eight peer education programs in the two study sites and their adjacent communities, with more programs in Mercato than Kasanchis. At the same time, the Kasanchis peer education programs included a larger number of peer educators, 388, compared to 165 peer educators in the Mercato-based programs The age ranges targeted was not consistent across programs. Some programs targeted "youth" up to age 30 , though most programs did include the age range 10 to 19 , some did not target younger adolescents, those below the age of 15 . All programs included young people aged 15 to 19 in their target population. All programs had content related to HIV education with some including family planning information and condom distribution.

Table 10: Profile of youth center and peer education programs in study area

\begin{tabular}{lcc}
\hline & Youth center & Peer education \\
\hline Total number of programs & 6 & 8 \\
$\quad$ Number of programs in Mercato & 5 & 6 \\
Number of programs in Kasanchis & 1 & 2 \\
Target Group* & & 5 \\
$\quad$ Number targeting age 10 to 14 & 4 & 7 \\
$\quad$ Number targeting age 15 to 19 & 5 & 553 \\
& - & 165 \\
Number of peer educators & - & 388 \\
$\quad$ Number of peer educators in Mercato & - & \\
Number of peer educators in Kasanchis & & \\
\hline
\end{tabular}

*Those targeting younger and older age groups are not mutually exclusive

Respondents were asked whether they had visited a youth center or been in contact with a peer educator in the last year. Young people who had migrated to the area in the last year were removed from analysis as their exposure to the area was limited. Youth centers appear to have limited coverage, with only 12 percent of adolescents having visited one in the previous year, compared to peer education which reached 20 percent of adolescents. Boys are significantly more likely to have utilized both youth centers and peer educators compared to girls. Twenty percent of boys have visited a youth center in the last year compared to only seven percent of girls, a difference that was statistically significant. Twentyseven percent of boys have had contact with a peer educator compared to only 15 percent of girls contacting a peer educator. 
Table 11: Percent of adolescents utilizing youth centers and peer educators in previous year, by sex and age group $(n=840)$

\begin{tabular}{lccccccc}
\hline $\begin{array}{l}\text { Type of } \\
\text { program }\end{array}$ & $\begin{array}{c}\text { All } \\
\text { Adolescents }\end{array}$ & $\begin{array}{c}\text { All } \\
\text { Boys }\end{array}$ & $\begin{array}{c}\text { All } \\
\text { Girls }\end{array}$ & \multicolumn{2}{c}{ Boys } & \multicolumn{2}{c}{ Girls } \\
\hline Youth center & 11.9 & $20.3^{* * *}$ & 7.2 & 10.5 & $27.2^{* * *}$ & 3.9 & $9.0^{*}$ \\
\hline Peer education & 19.6 & $26.5^{* * *}$ & 15.1 & 18.3 & $32.3^{* *}$ & 12.7 & 16.5 \\
\hline
\end{tabular}

Differences between groups significant at * $p<0.05 ;{ }^{* *} p<0.01 ;{ }^{* * *} p<0.001$

Older adolescents are significantly more likely to use adolescent programs than younger adolescents, a tendency which may, in part, reflect that some programs did not target younger adolescents. Older boys were more likely to access youth centers and peer education compared to their younger counterparts. A similar pattern held true for older versus younger girls. At the same time, boys in the younger age group were still more likely to use programs compared to girls in the older age group, a finding that underscores the extent to which programs are reaching boys to a far greater extent than girls. That older boys are more likely to be reached by youth programs is supported by earlier research amaong youth programs in Ethiopia ${ }^{10}$ (Mekbib, Erulkar, Belete, forthcoming).

Further analysis revealed that girls' participation in youth programs is significantly linked to workload, social connections, and mobility. The girls who are least likely to be reached by youth programs are those with the greatest workload, the smallest number of friends, and who are the most isolated and invisible, with the least mobility. At the same time, it is these girls who could be among the most vulnerable. For example, female domestic workers in the study worked an average of 62 hours per week, with 32 percent reporting that they had no friends at all. Contact with youth programs for these girls was extremely limited. Only 1 percent reported having been to a youth center and 6 percent reported having been in contact with a peer educator.

Many things have been said and have been told about HIV/ AIDS. But, it's very sad that it has not been practical. (Female age 10, Addis Ababa native, in school, 4 years of education)

\footnotetext{
${ }^{10}$ Researchers brought together staff from 15 youth serving organizations, mostly peer education programs and youth centers. Peer educators and youth club leaders collected information on who they were reaching, with the program beneficiaries dominated by older, in-school boys.
} 


\section{Implications for Programs}

\subsection{Recognize the diversity of young people}

Research and programs for young people tend to homogenize the adolescent population into one genderless mass, with little regard to age or social context. Adolescent boys and girls experience rapid, intense, and gendered changes between the ages of 10 to 19. The changes and needs experienced by a 12-year-old girl are considerably different from an 18-year-old boy, not to mention the differing nature of their relationships with family, culture and society. Yet, few programs acknowledge those differences. Instead, most programs implicitly assume that young people exist in a vacuum - that they have complete autonomy and control over what happens to them and that socio-cultural realities do not factor in. Greater segmentation of the adolescent population is needed in the design and content of programs, as well as greater attention to the specific circumstances of young people in local settings, especially vulnerable, hard-to-reach sub-groups of adolescents.

\subsection{Recognize the additional vulnerability of subgroups of adolescents}

This study demonstrated that young people are, in fact, diverse, and that many do not fit the common vision of adolescents. The majority of young people do not live with both parents and more than half of the girls live with neither parent. Not all adolescents are in school, with many of the most vulnerable being out of school, especially those living away from parents. Many adolescents are migrants and some have moved without family members. In the slums of Addis Ababa, one third of boys and nearly one half of girls migrated to the capital, mostly during early adolescence. Young people who have migrated from rural areas, most of whom are girls, are much more vulnerable than Addis Ababa natives. They are more likely to live without parents, more likely to be very poor, and more likely to work in low-pay, low-status jobs. Many of the migrant girls came to Addis Ababa to escape forced early marriage, and are not likely to have family support even in their places of origin. Many of these girls end up as domestic servants, an occupation that is lowly paid and often exploitive. Girls in this situation are highly vulnerable, both because they are at the mercy of others and because sex work often becomes a more viable option for such girls.

\subsection{Design programs that are appropriate to the context of young lives}

Programming for adolescents has centered on a small set of intervention models including youth centers, peer education, and youth friendly services. However, little attention has been paid to the in-built assumptions surrounding these models. For example, while peer education is a very popular program model, it assumes that young people have peers in the first place. Many of the young people, especially girls, reported that they have no friends. Not coincidentally, these very girls are the least likely to be reached by peer education. Youth centers assume that young people have the time to visit a center, that they feel safe enough to travel there, and that they feel comfortable in a mixed sex environment that is often 
dominated by older boys. In fact, these three conditions are not met for the majority of girls, especially in poor and/or traditional settings. Many of the most popular program models were designed in Western settings and based on the lives of young people in those settings. Surprisingly little program development has taken place based on indigenous African systems or based on local understanding of African adolescents. Likewise, few programs have benefited from a period of formative research, exploration and experimentation.

\subsection{Program content that acknowledges the complexity of young lives and the need for gender-specific safe spaces}

As programmatic models have been limited, so has the content of these programs, with most focusing on HIV or other RH topics, and little attention to other aspects of young lives. These data indicate that adolescents are in very different situations and face diverse challenges including those related to education, livelihoods and safety. Yet few programs acknowledge these concerns nor do they acknowledge the links between social and economic factors and RH outcomes, especially for girls. Ethiopia is a country of extremely high rates of HIV and high rates of poverty. Programs should acknowledge the links between poverty, powerlessness, and perhaps marriage, ${ }^{11}$ and HIV. When faced with no other means to support themselves, many girls in the poorest areas of Addis Ababa face no other option other than to sell sex for money; a considerable number of girls are coerced into sex against their will; and a large number of girls are forced to marry at a young age, with their sexual initiation effectively an act of rape. Current programming for adolescents hardly acknowledges child rights, human rights, or the developmental needs of young people.

As a result of this research, the Ministry of Youth Sports and Culture designed a program for young people in Addis Ababa. The program addresses the vulnerability and social isolation of young people by promoting single sex and age-specific safe spaces for girls and boys. The program will target especially vulnerable young people including those with no parents, younger youth, those with large workloads such as domestic workers, and isolated young people with few or no friends.

\footnotetext{
${ }^{11}$ There is emerging evidence that marriage may be a risk factor for hiv infection, with married adolescent girls in some African settings having significantly higher rates of infection compared to their unmarried sexually experienced counterparts. See Clark (2004) and Bruce and Clark (2004)
} 


\section{REFERENCES}

African Population and Health Research Center (APHRC). 2002. Population and Health Dynamics in Nairobi's informal Settlements. Nairobi: African Population and Health Research Center.

Ajayi, A, et al. 1997. "Schooling and the Experience of Adolescents in Kenya," Nairobi: Ministry of Education and Population Council, December, 1997.

Brockerhof M, Brennan E. 1998. "The poverty of cities in developing countries" Population and Development Review 24(1):75-114.

Bruce, J. 2002. "Preparing the Twenty-First Century's First Generation of Adults: Policy and Program Perspectives" Population Council paper commissioned by UNFPA, June

Bruce J, Clark S. 2004 "The implications of early marriage for HIV/AIDS policy" brief based on background paper prepared for the WHO/UNFPA/Population Council Technical Consultation on Married Adolescents. New York: Population Council.

Clark S, 2004. "Early marriage and HIV risks in sub-Saharan Africa" Studies in Family Planning, 35(3) 149-160.

COFAP (Consortium of Family Planning NGOs). 2002. "Profile of Reproductive Health NGOs in Ethiopia," Addis Ababa, September.

CRDA (Christian Relief and Development Association). 2000. "Members Directory" Addis Ababa, November.

"Facts about adolescents from Demographic and Health Surveys: Statistical tools for program planning: Ethiopia." New York: Population Council, 2000.

Jessor R, Turbin MS, Costa FM. 1998. "Risk and protection in successful outcomes among disadvantaged adolescents" Appl Development Science 2(4) 194-208.

Karim AM, Magnani R, Morgan GT, et al. 2003 "Reproductive health risk and protective factors among unmarried youth in Ghana" Intl Family Planning Perspectives 2003; 29(7), March.

Kish L, 1965. Survey Sampling, New York: Wiley.

Mekbib T. Erulkar AS, Belete F. forthcoming. "Who is being reached by yough programs: Results of a capacity building exercise in Ethiopia." Ethiopian Journal of Health and Development.

Rani, M, and E Lule. 2004. "Exploring the socioeconomic dimension of adolescent reproductive health: A multicountry analysis." International Family Planning Perspectives, 30(3):110-117.

Resnick MD et al. 1997. "Protecting adolescents from harm." JAMA, 278(10):823832.

Tilsen D, Larsen U. 2000. "Divorce in Ethiopia: The impact of early marriage and childlessness" J Biosoc. Sci, (32)355-372.

Zulu, E, Ezeh A, Dodoo F. 2000. "Slum residence and sexual outcomes: Early findings of causal linkages in Nairobi, Kenya," Nairobi: African Population and Health Research Center Working Paper No. 17. 
